\title{
The role of novel 3D point contact transmission in ship noise pollution reduction
}

\author{
Alexei Popov ${ }^{1}$, George Nerubenko ${ }^{2}$ \\ ${ }^{1}$ Mechanical Department, National University of Shipbuilding, Nikolaev, Ukraine \\ ${ }^{2}$ NER*MAR Limited, Toronto, Canada, National University of Shipbuilding, Nikolaev, Ukraine \\ Email address: \\ optimalproject@hotmail.com (G. Nerubenko)
}

\section{To cite this article:}

Alexei Popov, George Nerubenko. The Role of Novel 3D Point Contact Transmission in Ship Noise Pollution Reduction. Journal of Water Resources and Ocean Science. Special Issue: Safe Technology and Pollution Free Environment. Vol. 4, No. 1-1, 2015, pp. 11-19. doi: $10.11648 /$ j.wros.s.2015040101.12

\begin{abstract}
The ship noise causes marine pollution problems. The gear transmission contributes a significant part to ship noise. The replacement of regular gears by novel 3D point contact tooth gears is considered. The reduced noise levels up to $19 \mathrm{dBA}$ are the advantages of transmissions based on invented gears having 3D point system of engaging. The implementation of invented novel transmission gives the opportunity of providing the industry by safe equipment allowing reduce the important component of ocean pollution, i.e. noise pollution.
\end{abstract}

Keywords: Ship Gear Transmission, 3D Point Contact Tooth Gears, Tooth Contact Stresses, Marine Noise Pollution

\section{Introduction}

The usage and exploitation of water resources brings the people to problem of providing pollution free environment. It should be achieved when exploiting technology is safe and designed specially for meeting the environment requirements. Ships [1], [2] provide the significant input to the marine noise pollution. Noise from the ship is disrupting marine life where almost every living creature depends on sound as a primary sense [3] - [5] for mating, hunting, and survival. Sound travels more rapidly and over larger distances in the sea than in the atmosphere. One of the ship's noise sources is a main transmission. It is necessary to say that a main transmission is in diesel, steam - and gas - turbine powered ships. Despite of different types of power source, a transmission in these ships has a great impact on overall noise levels. Marine engineers are trying reducing the transmission noise level by using the advanced approaches. Increasing challenges on reducing ocean noise pollution has opened the new directions in ship transmission technologies. The example of such technology implemented in geared transmission is the usage of novel type of gears with 3D point system of mesh engaging which was invented, patented and developed by Alexei P. Popov. The paper identifies the milestones of R\&D that were undertaken to create the new type of geared transmission having reduced noise levels. The new shapes of tooth forced the engineers to build ship transmissions with high stress capacity and low levels of noise. The presented results of theoretical analysis combined with experiments illustrate the effectiveness of developed approach. The synthesis of new type of gearing is presented. The implementation of invented novel transmission gives the opportunity of providing the industry by safe equipment allowing reduce the important component of a marine pollution, i.e. noise pollution. An engine's geared transmission is loaded by external and internal forces during operation. The purpose of geared transmission is to deliver engine torque to vehicle wheels within the narrow proper range of engine's rotational speeds. So the transmission uses gears to make the engine's torque more effective, and to keep the engine operating at an appropriate speed. Traditionally gears are designed in an assumption that the gear teeth are subjected to the Hertzian contact compressive stresses, deformations and elasto-hydrodynamic lubrication. The main factors impacting on the character and intensity of teeth wear are the contact compressive stresses and deformations. Thin under-surface layers of tooth are the most stressed areas of gear material. The big value of stress gradients are monitored in these layers. The main aspects of Hertz assumptions [6] - [8] for contact problems would be 1. a surface of contacting bodies are perfectly smooth, isotropic, and homogeneous, 2. the deformations are elastic only, 3. the squeezing press force is normal to contact spot area, 4. the dimensions of contact spot area are very small in comparison to characteristic sizes 
of contacting bodies. The Hertz theory was improved by hundreds of scientists and engineers during last 100 years, see for instance [11] - [16], [23] - [28], [32] - [33]. Some of the researches deviated from Hertz theory and took for base of their calculations the Non-Hertzian contact approach for the explanation of new phenomena in contacting objects. Such approach could be found, for instance, in [17] - [19] dedicated to Non-Hertzian contact of elastic spheres. Professor Alexei P. Popov using the Winkler hypothesis [20] - [22] had found [9], [10] that the point contact interaction of teeth could be characterized by certain values of a contact stresses which are significantly lower than the values of a contact stresses for teeth having linear contacting touch. This invention provides the opportunity for increasing of the tooth load capacity, the reduction of sizes and weights, and a reduction of noise and vibration. The measured numbers of overall noise reduction in tested prototypes of the marine transmissions is up to $19 \mathrm{dBA}$.

\section{Introduction of Gears with 3D Point System of Mesh Engaging}

Nowadays the Hertz formula (with the several correcting coefficients) is developed for an analysis of a linear contact phenomenon in the gearings with a point contact such as the hypoid gear transmissions, the spiral bevel transmissions and the Novikov's transmissions. The Hertz theory does not reflect the physical idea of stressed tooth condition. In reality the engineer is facing the volumetric 3D stressed operation during contact interaction of teeth for such type of gearing. This lack of conformity to experimental values and the disharmony in explanation of test results regarding values of maximum strengths Qmax pushes the research efforts for construction of new theory of contact strength and invention of new profiles of teeth. The confirmation of proof is based on new theoretical and experimental studies of point contact in statics and dynamics on prototypes.

New approach is proposed by Professor Alexei P. Popov. The developed theory [9], [10] is based on obtaining of two equally weighted functions of the contact deformations. First function of the contact deformations is determined for the contacting objects taking into consideration their shapes and changes in shape before and after load. The Winkler hypothesis is used for determination of second function. The Winkler hypothesis was improved in [9], [10] and the area of its application was expanded and enlarged, specifically for solution of $3 \mathrm{D}$ point contacting systems. The proposed approach [9], [10] introduces the cause - effect relationship between the function of a contact deformations and a function of a contact stresses. The function of contact deformations is the cause or principle. It is reflecting the function of a contact stresses, which is the consequent result or outcome. It is assumed in invented model that patented gear design could lead to new modified shapes of contacting tooth. Under the load in the contact area of a gear pair the observer could see a sort of "point". This "point" looks like microscopic ellipse. Technically this fact is confirmed by experiments. During proposed modeling the area of point contact is presented by elliptical area. According to above mentioned approach [9], [10] the equations for maximum contact stresses Qmax and size of elliptical area of a contact are obtained from the following model of a contact (see Figure 1).

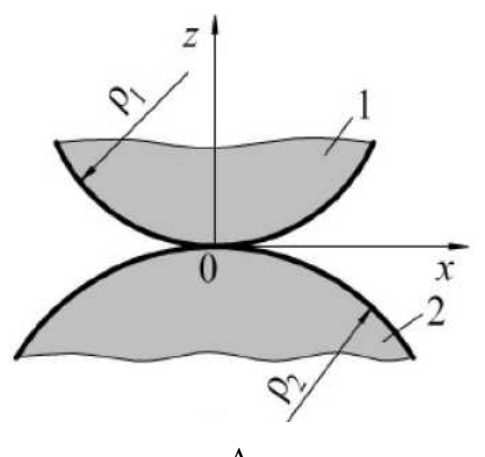

A

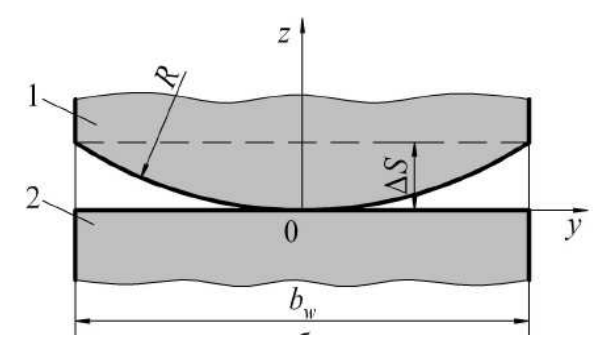

B

Figure 1. The model for calculations: teeth contact in plane z0x (A) and contact of cylinder with plane in projection on coordinate plane z0y $(B) ; 1$ pinion tooth, 2 - gear tooth.

The introduced model is characterizing by external and internal touching contact of round cylinders having radii in $\mathrm{r} 1$ and $\mathrm{r} 2$ in $\mathrm{z} 0 \mathrm{x}$ plane (see Figure 1A), and by interaction of cylinder of radius $\mathrm{R}$ with certain plane having width of $b_{w}$ in mutually perpendicular z0y plane (see Figure 1B). It is necessary to underline that the contact in both planes has point nature despite the fact that there is a contact of round cylinders in z0x plane as shown in Figure 1A, and there is a contact of cylinder and flat plane in z0y projection as shown in Figure $1 \mathrm{~B}$.

There is a model of proposed pinion tooth having the side surfaces designed with help of curve lines in Figure 2. There is the basic tooth shape in Figure 2 having radii in $\mathrm{r} 1$ similar to one shown in Figure 1A. The width of tooth is bw in Figure 2, similar to one shown in Figure 1B. The form radii are $\mathrm{R}$ in Figure 2, similar to one shown in Figure 1B.

The solutions for teeth contact problems for linear and nonlinear relationship between elastic deformations of teeth and outcome stresses are obtained. Following the formulas derived in [10], the maximum point contact stress Qmax would be determined as

$$
\mathrm{Qmax}=0.33 \mathrm{Zj}\left(\mathrm{Kj} \mathrm{a}(\mathrm{a}+\mathrm{v})^{2} \mathrm{E}^{2} \mathrm{To} /\left(\mathrm{rw}^{2} \mathrm{Rp}\right)\right)^{1 / 3}
$$

where (from Figure1 and Figure2)

$$
\mathrm{a}=(\mathrm{r} / \mathrm{R})^{1 / 2}
$$




$$
\mathrm{R}=\mathrm{bw}^{2} / 8(\mathrm{dS}) .
$$

and according to [10]: $\mathrm{Rp}$ - pitch radius, $\mathrm{Kj}$ is the product of coefficients including the contact stress coefficient, the coefficient reflecting the influence of type of engine on the contact tooth strength and other coefficients proposed in [10], $\mathrm{Zj}$ is the combination of coefficients determined in [10].

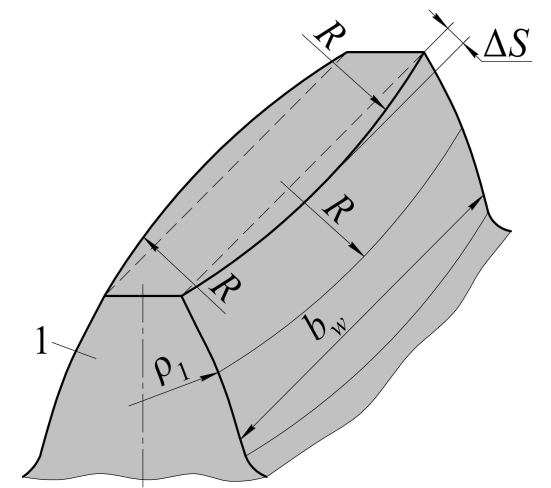

Figure 2. The general view of tooth for modified pinion

Linear or nonlinear contact properties are modeled by the geometrical deviation parameter $\mathrm{dS}$, which could be estimated using the linear or nonlinear assumptions.

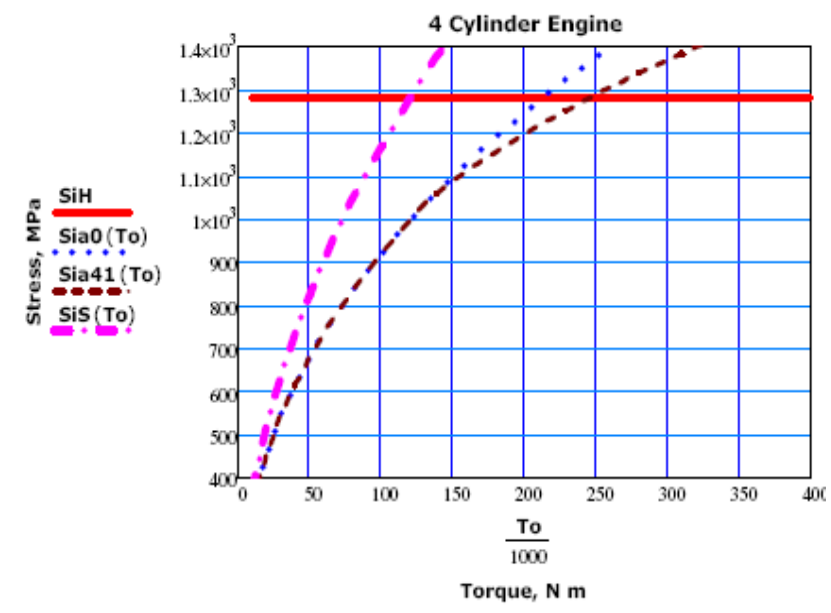

Figure 3. The contact stresses. 4 cylinder engine application.

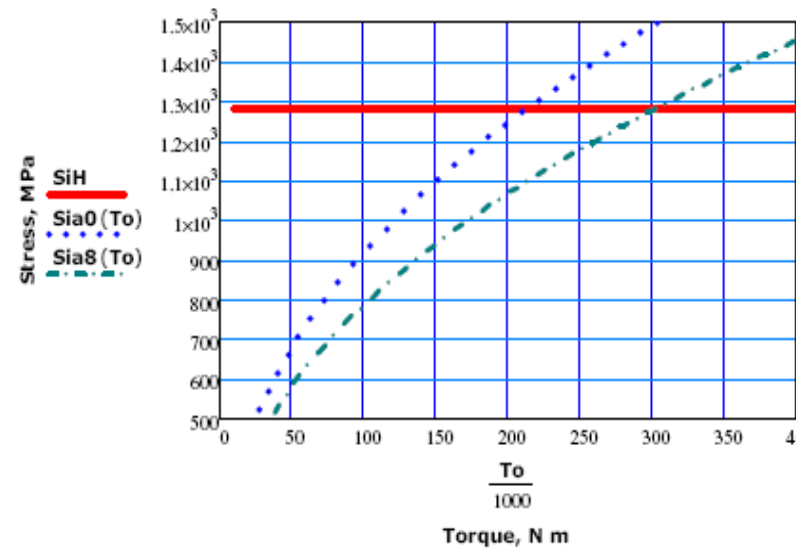

Figure 4. The contact stresses. 4 cylinder engine vs. 8cyliner engine.

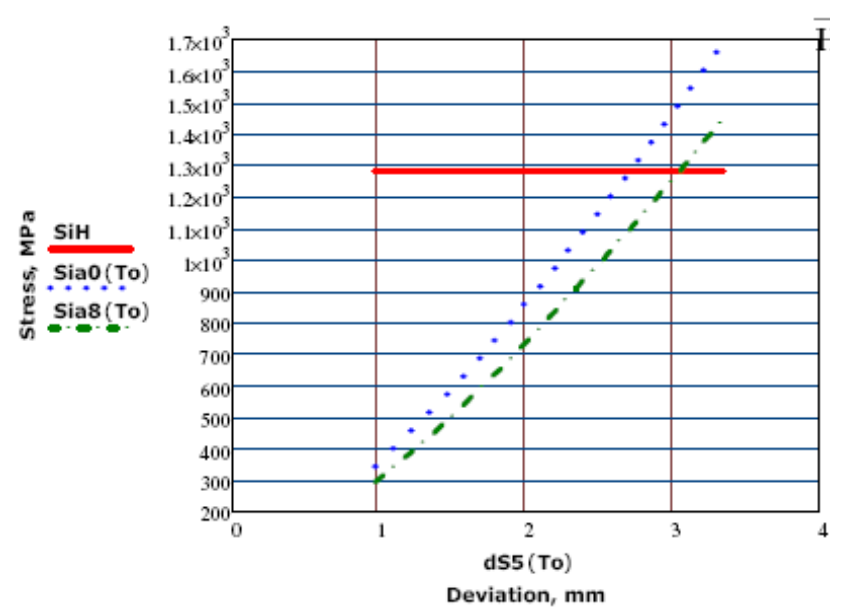

Figure 5. The contact stresses vs. deviation numbers.

The following example of calculations was formed for the illustrative purpose. The prototype of geared reducer has several shifts. The prototype of geared reducer has several shifts. The considered example is for $1^{\text {st }}$ shift [10] of the transmission having point mesh. Parameters of $1^{\text {st }}$ shift are $\mathrm{z} 1$ $=33 ; \mathrm{z} 2=127$ (ratio is 3.85 ); $\mathrm{m}=4 \mathrm{~mm} ; \mathrm{aw}=20$ degrees; $\mathrm{bw}=$ $77 \mathrm{~mm} ; \mathrm{rw}=17,916 \mathrm{~mm} ; \mathrm{v}=0.3 ; \mathrm{E}=2.1 \times 10^{5} \mathrm{MPa}$. The allowable compressive stress for selected material and surface hardness is calculated based on recommendation of [11], and would be $1282 \mathrm{MPa}$. The estimates are done for a model of linear or nonlinear contact properties. The direct calculations were used for evaluation of contact stresses (1) for a case of linear contact properties, and the final element technique was used for a case of nonlinear contact properties. The graphical interpretation of analysis is presented in Figures 3, 4, and 5. The ordinate axis is standing for compressive stress numbers in these graphs. The abscissa axis is for torque magnitudes To in Figure 3 and Figure 4. The deviation numbers dS are given in the abscissa axis in Figure 5. The red solid straight line is reflected the value of allowable compressive stress in this gear pair in Figures 3-5. The Figure 3 is the graphical illustration of contact stress calculations for transmission used for 4 cylinder engine.

There are three curves are shown in Figure 3. Brown dashed curve is reflecting the relationship between the applied torque and the contact compressive stresses for linear model, and blue dotted curve is showing the dependence of the contact compressive stresses from applied torque for nonlinear model. The dash - dotted pink curve is built using the standard formulas (for instance see [11], [25], [26]) for stress estimates in traditional contact case, namely in a case with "the line of a contact". The comparison of calculations for "the line of a contact" case (a dash - dotted pink curve) and "the point of a contact" case (a blue dotted curve) demonstrates that for low loads (low values of torque) both curves are practically coincided, but when the value of applied torque is increasing the load capacity of gear is higher for case of point contact. In given example the maximum stress would be reached at torque of $120 \mathrm{~N} \mathrm{~m}$ for "the line of a contact" case, and maximum stress would be reached at torque of $220 \mathrm{~N} \mathrm{~m}$ for "the point of a contact" case. Further analysis shows that for 
the lower values of torques the both curves reflecting the point contact case are practically coincided up to value of torque of $125 \mathrm{~N} \mathrm{~m}$.

The nonlinear model analysis demonstrates that the maximum value of stress could be reached at torque of $220 \mathrm{~N}$ $\mathrm{m}$, while the maximum value of stress for linear model would be at torque of $250 \mathrm{~N} \mathrm{~m}$. The received result could help for formulation of the recommendation - use the nonlinear model for having conservative safety factor. The influence of engine type ( 4 cylinder engine vs. 8 cylinder engine) is shown in Figure 4. The blue dotted curve still is reflecting the relationship between the applied torque and the contact compressive stresses for transmission used with 4 cylinder engine (nonlinear model), and green dotted - dashed curve is reflecting the relationship between the applied torque and the contact compressive stresses for transmission used with 8 cylinder engine (similar nonlinear model). The replacement of 4 cylinder engine to 8 cylinder engine allows increasing of torque (in considered case from $220 \mathrm{~N}$ m to $300 \mathrm{~N} \mathrm{~m}$ ) keeping the same level of contact stress in gear pair. Figure 5 gives the idea of relationship between parameter dS (torque dependent) and contact stresses (nonlinear model is applied). The blue dotted curve is reflecting the relationship between the applied torque and the contact compressive stresses for transmission used with 4 cylinder engines, and green dotted - dashed curve is reflecting the relationship between the applied torque and the contact compressive stresses for transmission used with 8 cylinder engines. The analysis of curves demonstrates that the magnitude of parameter $\mathrm{dS}$ is increasing with torque rise and simultaneously this increase is forcing to increase of the contact stresses. The maximum contact stress (in case of 4 cylinder engine) corresponds to value of deviation $\mathrm{dS}$ of 2.7 $\mathrm{mm}$, while the maximum contact stress (in case of 8 cylinder engine) corresponds to value of deviation $\mathrm{dS}$ of $3.1 \mathrm{~mm}$.

\section{Static Experiment Results}

In order to identify the applicability of introduced theory and to make its verification, a series of experimental tests were employed. First of all the static tests were executed [10]. There was contact compressive imitation of two cylinders loaded by force $\mathrm{Fn}$; the circle cylinder with radius $\mathrm{r} 1=60 \mathrm{~mm}$ was contacting the barrel - shaped cylinder with maximal radius $\mathrm{r} 2$ $=40 \mathrm{~mm}$. The form radius of a barrel shape was $\mathrm{R}=41.667 \mathrm{~m}$. The length of cylinders was $b_{w}=100 \mathrm{~mm}$. The force Fn was applied several times as step load in range of $10000 \mathrm{~N}-30000$ $\mathrm{N}$, step equal to $10000 \mathrm{~N}$.

The minor axis 2Aa (conjugate diameter) of elliptical area of a contact could be calculated from formula

$$
\mathrm{Aa}=1.202(\mathrm{a} \mathrm{rw} \mathrm{Fn} /(\mathrm{a}+\mathrm{v}) \mathrm{E})^{0.33}
$$

The major axis $2 \mathrm{Bb}$ (transverse diameter) could be calculated from formula

$$
\mathrm{Bb}=1.202\left(\mathrm{rw} \mathrm{Fn} / \mathrm{a}^{2}(\mathrm{a}+\mathrm{v}) \mathrm{E}\right)^{0.33}
$$

The summary results of test are presented in Figure 6 (for minor axis $\mathrm{Aa}$ ) and in Figure 7 (for major axis $\mathrm{Bb}$ ) as a comparison of calculated values of minor axis $2 \mathrm{Aa}$ of elliptical area of contact and major axis $2 \mathrm{Bb}$ vs. experimentally obtained data. The theoretical values of minor axis $2 \mathrm{Aa}$ and major axis $2 \mathrm{Bb}$ were determined using the nonlinear model. The analysis of data presented in Figures 6 and 7 shows very good compliance of theoretical estimated with test results. The obtained maximum relative deviation is $2.8 \%$. The mean value of relative deviations for minor axis $2 \mathrm{Aa}$ was $1.41 \%$ in tests, and the mean value of relative deviations for major axis $2 \mathrm{Bb}$ was $1.32 \%$. The obtained maximum relative deviation for value of tested elliptical area is $3.3 \%$, and means value of relative deviations is $2.3 \%$. The results of test confirm the satisfactory coincidence of configurations of modeled and real contact zones. There is a sample of a computer formed image of the stress distribution on a contact point (spot) for pinion tooth in Figure 8. The picture is confirming the theoretical assumption about elliptical area. The stress values in contact point are over $700 \mathrm{MPa}$ in given example, in zones far from center of contact the stress values declined to $400 \mathrm{MPa}$. The shape of contact zone resembles the ellipse.

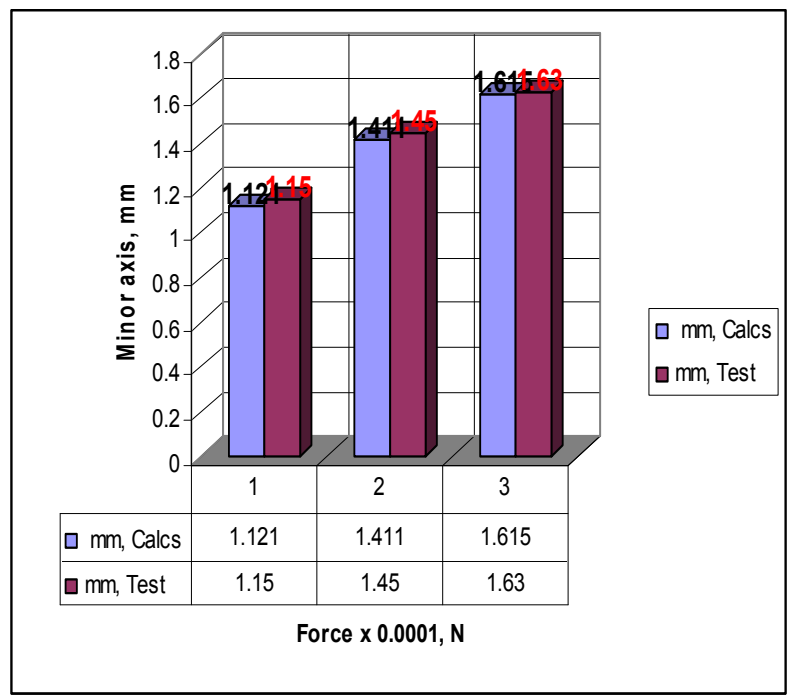

Figure 6. The comparison of calculations and test results for minor axis.

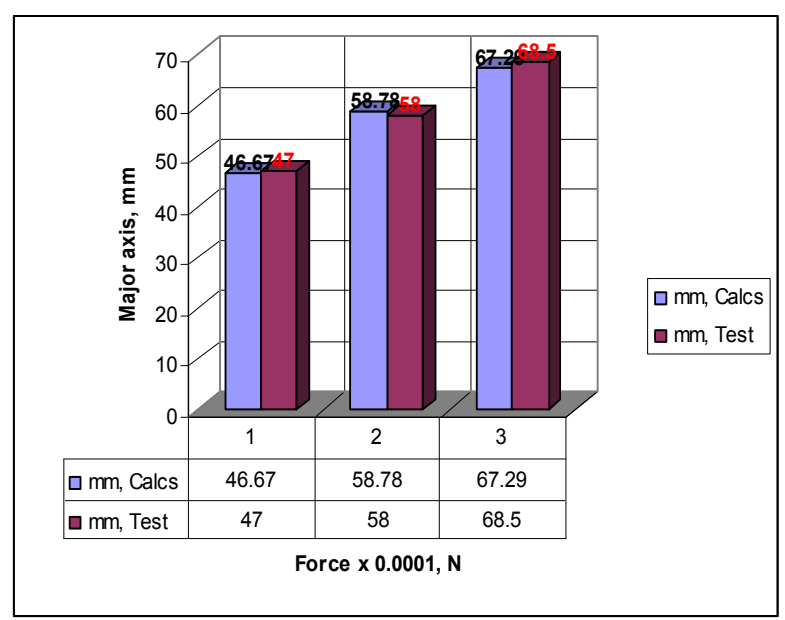

Figure 7. The comparison of calculations and test results for major axis. 


\section{Ship Transmission Tests}

The propeller of ship is driven by Main Engine (see Figure 9). The Main Engine could consist of one or several prime movers. Prime drive could be steam turbine, gas turbine or diesel. Engines must operate at relatively high speeds for maximum efficiency. Propellers must operate at lower speeds for maximum efficiency. The prime drive or engine could have higher operational angular velocity, so it is necessary to put the special device between engine and propeller for the reduction of engine's rotation speed. Therefore, reduction gears are used to allow both the engine and the propeller to operate within their most efficient revolutions per minute (RPM) intervals. The usage of gears is by no means limited to ship propulsion. Other machinery, such as ship's service generators and various pumps, also has reduction gears. Reduction gears are classified by the number of steps used to bring about the speed reduction and the arrangement of the gearing. A gear mechanism consisting of a pair of gears or a small gear (pinion) driven by the engine shaft, which directly drives a large (bull) gear on the propeller shaft, is called a single-reduction gear. In this type of arrangement, the ratio of speed reduction is proportional to the ratio of diameters of the pinion and the gear. In mechanical drives, reversing the direction of rotation of the propeller shaft may be accomplished in one of two ways. It could be reverse of the direction of engine rotation or the usage of the reverse gears. Reverse gears are used on marine engines to reverse the rotation of the propeller shaft during maneuvering without reversing the rotation of the engine.

The device named as a reducer or reduction transmission is shown in Figure 9. Figure 9 reflects the typical equipment configuration for ship propulsion. The reduction mechanism is based on gears with teeth. The noise emitting by gear reducer has a significant impact on marine noise pollution. Hence the improvement of teeth profiles from point of view of reduction of noise levels could be the perspective way of fighting with marine pollution.

It was designed and manufactured the prototype a of ship reducer with two types of gear teeth: first type was based on regular profiles, and second type was based on profiles shown in previous study made by Professor Alexei Popov. The tested reducer had spur or straight-cut gears with point contact. Actually the designed and tested transmission is a prototype of $1^{\text {st }}$ box of heavy ship reduction transmission. The photo of manufactured prototype is presented in Figure 10.

The presented prototype is the 2 stage gear reducer. Applied nominal power Po is $5250 \mathrm{~kW}$. The power is split by three streams on 1st shift (see Figure 11). The nominal speed of rotation of entering first shaft is 12840 RPM. First shaft has a pinion (see Figure 12). Initially the length of teeth of pinion was $135 \mathrm{~mm}$; this length was reduced to $77 \mathrm{~mm}$ in modified pinion (see left side and right side photos in Figure 12). In other words the reduction of pinion teeth length was in 1.75 times. The point contact was provided by changing of teeth profile in accordance to [29] - [31]. The straight formation lines of side surfaces were substituted by the curved formation lines having the radius of curvature as $\mathrm{R}=61.7 \mathrm{~m}$. The teeth of geared wheels are made with deep profile and their addendum (radial distance from the pitch surface to the outermost point of the tooth) was 1.25 of module. The angle of action was aw $=$ 20o. The profile modification was done for dedendum and addendum of pinion teeth for improving the teeth interaction during entering and exiting. The special program «Aeroflank» was used for the abovementioned modification. The heavy transmission was manufactured in ZORYA Company facility (Nikilaev - city, Ukraine), and modification of pinion teeth was done in Ukrainian company MOTOR - SICH (Zaporoghye - city) on Gear Profile Grinding Machine Gleason-Pfauter 600. The tests were arranged in ZORYA Company facility. The load regimes were selected in interval of $0.4-1.2$ of applied power Po as shown in Figure 13. In this Figure 13 the red triangles indicate the applied power in each load regime. There are numbers of RPM (which are correspondent to each load) shown in Figure 14.The total amount of cycles of loads was $128 \cdot 10^{6}$, and as follows from Figure $15-90 \%$ of total amount of cycles $\left(115.56 \cdot 10^{6}\right)$ was measured for nominal regime of load, and 3.6\% cycles were measured for overload regime. The number of cycles of loads was in accordance to recommendations for industrial standard test requirements [26]. It was no damages, stops, recorded deviations during transmission test. The transmission was disassembled and inspected after test; all teeth of gears are in good shape, all parts are in operational conditions, no complains or admonitions. The following factors were taking into consideration during design: a. the expected increasing of contact and bending flexibilities of contacting pairs of teeth of 1 st shift, b. the increased flexibility of a clamping area of a bottom of dedendum and pinion shaft of teeth having $77 \mathrm{~mm}$ width (instead of regular $135 \mathrm{~mm}$ width), c. the raised overlap coefficient of gearing caused by deep profile, $d$. the number of micro-impacts during contacting of pair of gears was radically reduced for the modified pinion in comparison to regular pinion. That fact led to noise level reduction caused by contacting gears.

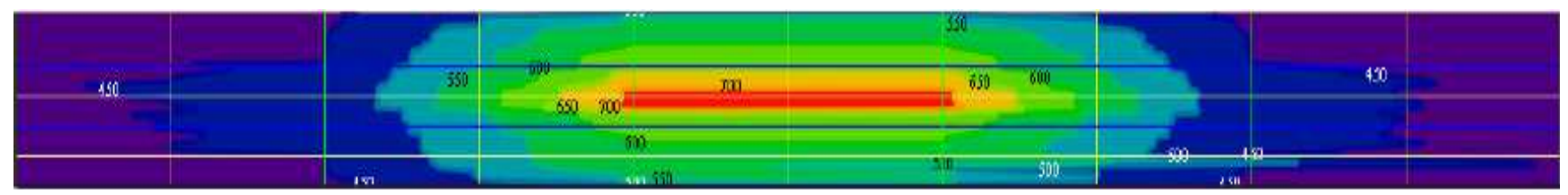

Figure 8. The computer formed image of the tooth contact stresses. 


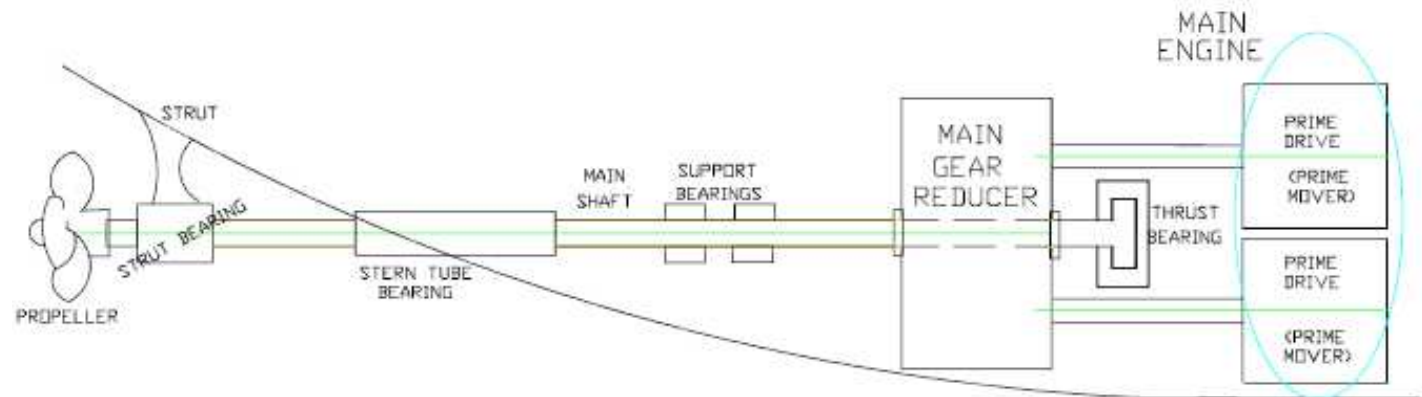

Figure 9. General scheme of ship's prorultion.

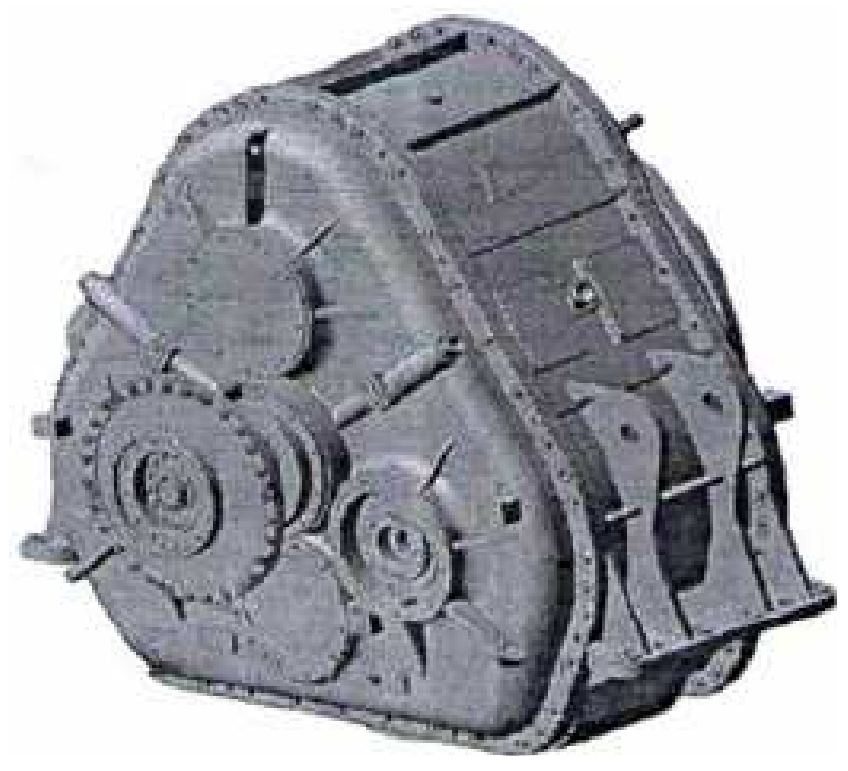

Figure 10. Photo of prototype of ship's gear reducer.

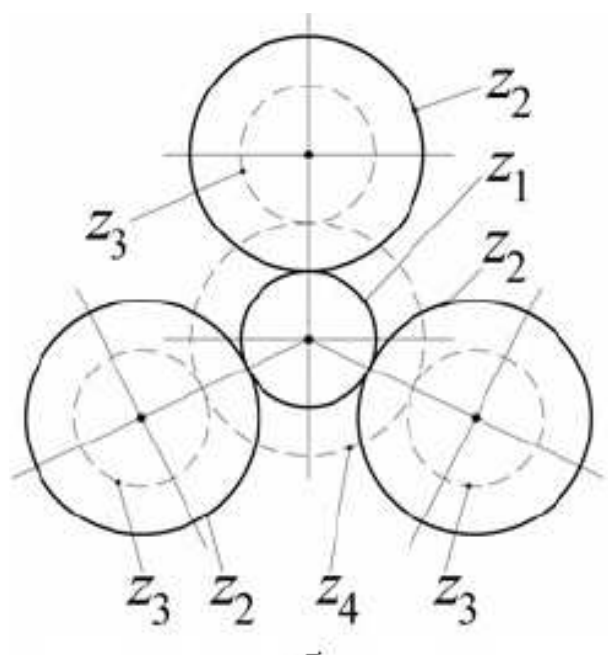

Figure 11. The kinematic scheme of reducer
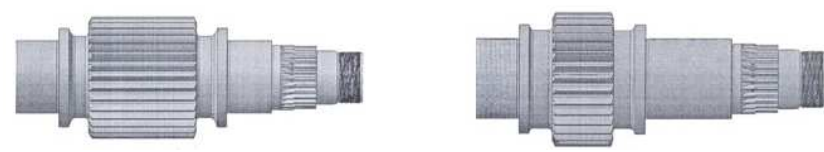

Figure 12. Photos of $1^{\text {st }}$ stage pinion

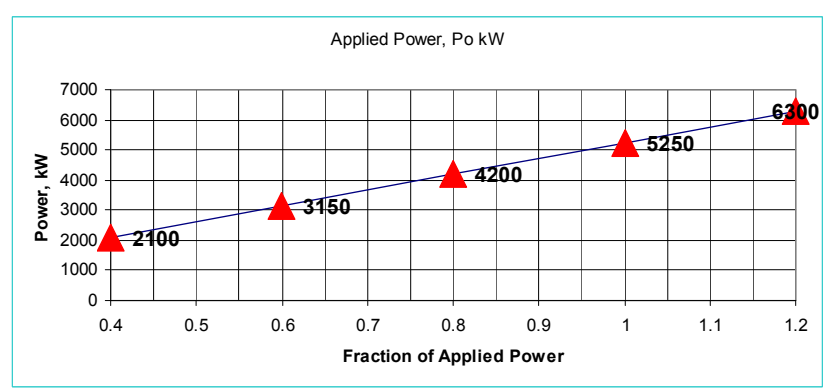

Figure 13. The ship transmission load regimes

The design calculations demonstrated that the predicted reduction of overall noise would be $11.8 \mathrm{dBA}$. The acoustic engineer recorded the reduction of overall level of noise as 12 $\mathrm{dBA}$ during the noise measurement session.

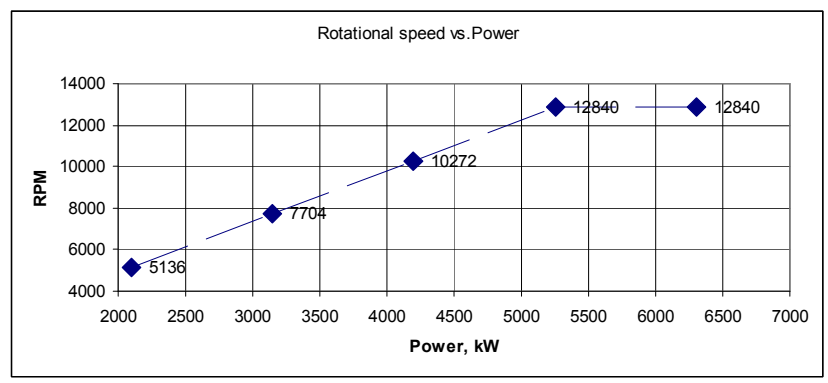

Figure 14. RPM numbers for selected load regimes.

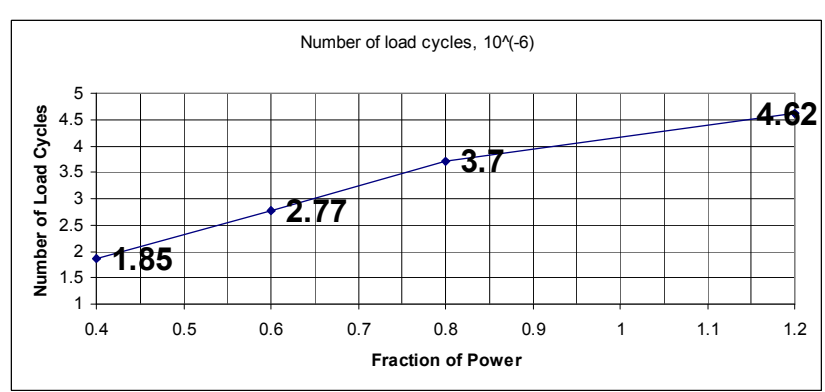

Figure 15. Amount of cycles for selected load regimes.

Now this reducer shown in Figure 10 having the kinematic scheme shown in Figure 11 (with modified pinion shown in right side of Figure 12) is still in operation. 


\section{Boat Reducer Noise Tests}

Several tests were arranged for detailed study of the noise reduction in reducer having proposed modified gears. The 2 stage reducing marine transmission was selected for tests. The gear reducer is installed in boat equipped by IVECO Marine Propulsion 6-cylinders Diesel Engine N67 MNT M28 having $132 \mathrm{~kW}$ at $2500 \mathrm{RPM}$ (heavy duty). The Engine performance torque is $560 \mathrm{~N} \mathrm{~m}$ at $1800 \mathrm{RPM}$. The maximum no load governed speed at max rating is $3150 \mathrm{RPM}$. The performance graph Torque vs. RPM is shown in Figure 16.

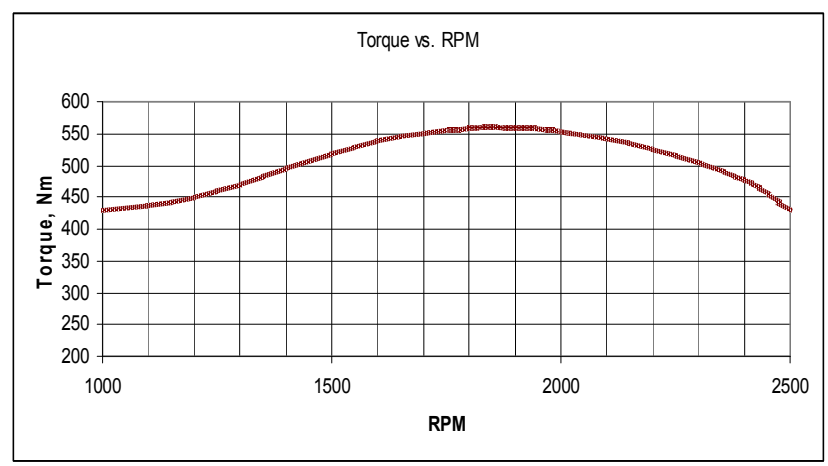

Figure 16. Torque vs. RPM. Engine N67 MNT M28.

The installed gear ratios for selected reducer are: $1^{\text {st }}$ stage is $3.00: 1,2^{\text {nd }}$ stage is $1.67: 1$. Test rig layout was organized in a similar way as for a test stands described in [34], [35]. The direct current electric motor, tested transmission gearbox and electrical brake are residually mounted on rig stand frame. The gearbox was powered by the electric motor and consumes its power on a brake. The transmission noise level was measured on a test stand by sound pressure level (SPL) meter microphone located above the centerline of gearbox surface at a distance of $1 \mathrm{~m}$. Octave Band Spectrum was recorded in each session by that microphone, and the center frequencies for these bands were: $31.5 \mathrm{~Hz}, 63 \mathrm{~Hz}, 125 \mathrm{~Hz}, 250 \mathrm{~Hz}, 500 \mathrm{~Hz}$, $1 \mathrm{kHz}, 2 \mathrm{kHz}, 4 \mathrm{kHz}, 8 \mathrm{kHz}$ and $16 \mathrm{kHz}$. The measurement methodology and procedure were based mainly on recommendations of [36]. The experiment consisted of two phases and preliminary Background Noise test. For Background Noise test the transmission gearbox was excluded from test and DC electrical motor was connected to brake directly. The tests were done for the following values of motor's rotational speed: 1000 RPM, 2000 RPM, and 3000 RPM. The brake load was provided the torques equivalent to those which were reported for performance curve and the same values of RPM (see Figure 16), i.e. $424 \mathrm{~N}$ m at 1000 RPM, $552 \mathrm{~N} m$ at $2000 \mathrm{RPM}, 483 \mathrm{~N}$ m at $3000 \mathrm{RPM}$ The main result of a preliminary test have demonstrated that measured overall noise levels were less than $60 \mathrm{dBA}$. The original transmission (with regular fabricated gears) was tested during first phase. The tests were done in the equivalent format as for preliminary Background Noise test. The detailed gear inspection after first phase test demonstrated that the gear's teeth were in good operational conditions, there were no visible defects, fatigue spots or damages of surfaces of teeth.
The gear replacement was made for second phase. The modified gears were manufactured using the recommendations and formulas from [9], [10], [29] - [31]. All shafts and other parts had the same geometry and dimensions as the regular ones. Everything was assembled within regular box. It gave the opportunity to compare "apples to apples" during experiment. The modified transmission (with new modified manufactured gears) was tested during second phase. The tests were done in the same manner as for first phase test. The comparison of obtained results during first and second phase tests to levels recorded during preliminary tests brought to conclusion that the corrections for background noise could be ignored. The relationship between the noise levels and rotational speed for different cases of usage of gears (regular vs. modified) were studied and recorded during first and second phases (see Figures 17-19 and 20-22).

The analysis of test measurements data brings to a conclusion that the substitutions the regular gears in transmission by proposed modified gears yields to reduce the overall noise levels in total interval of operating loads and speeds of rotation.

The range of recorded noise reduction is sitting in interval of $12 \mathrm{dBA}-19 \mathrm{dBA}$ (see Figure 23).

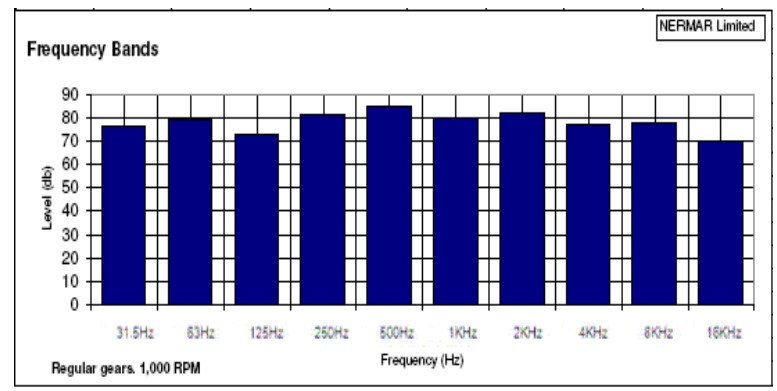

Figure 17. Regular gears. 1000 RPM. Overall noise level is $90 \mathrm{dBA}$.

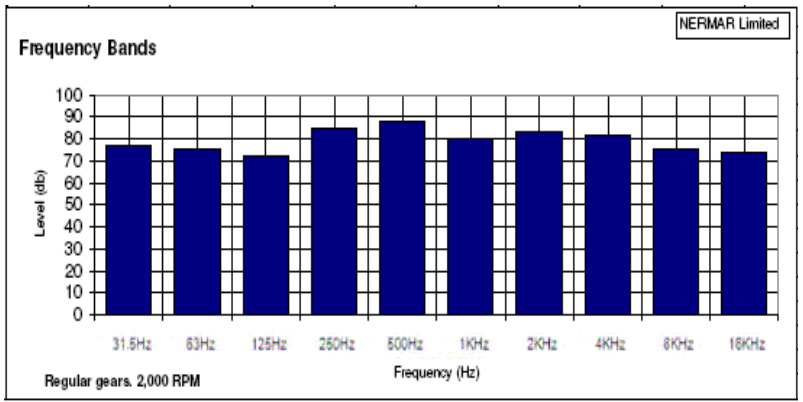

Figure 18. Regular gears. 2000 RPM. Overall noise level is $92 \mathrm{dBA}$.

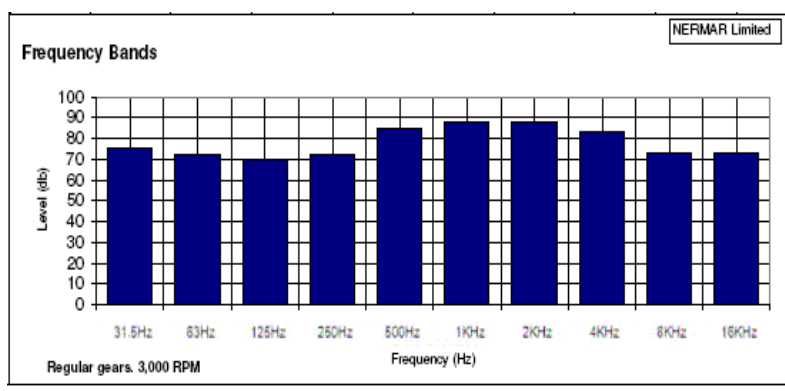

Figure 19. Regular gears. 3000 RPM. Overall noise level is $93 \mathrm{dBA}$. 


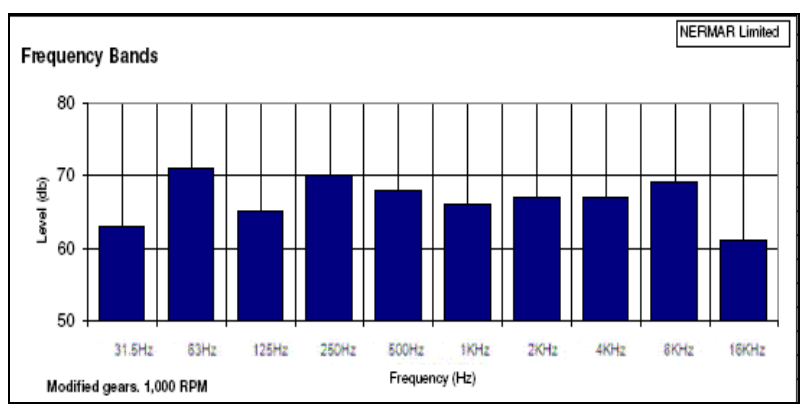

Figure 20. Modified gears. 1000 RPM. Overall noise level is $78 \mathrm{dBA}$.

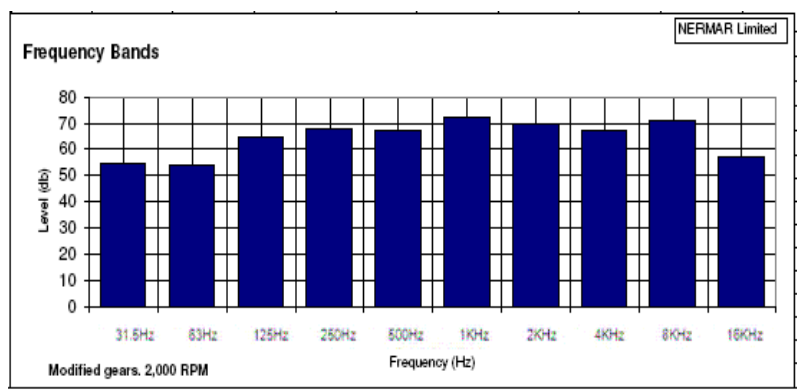

Figure 21. Modified gears. 2000 RPM. Overall noise level is $78 \mathrm{dBA}$.

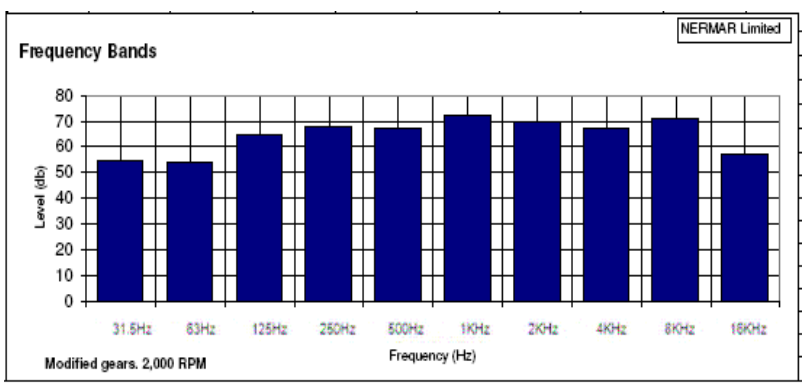

Figure 22. Modified gears. 3000 RPM. Overall noise level is $74 \mathrm{dBA}$.

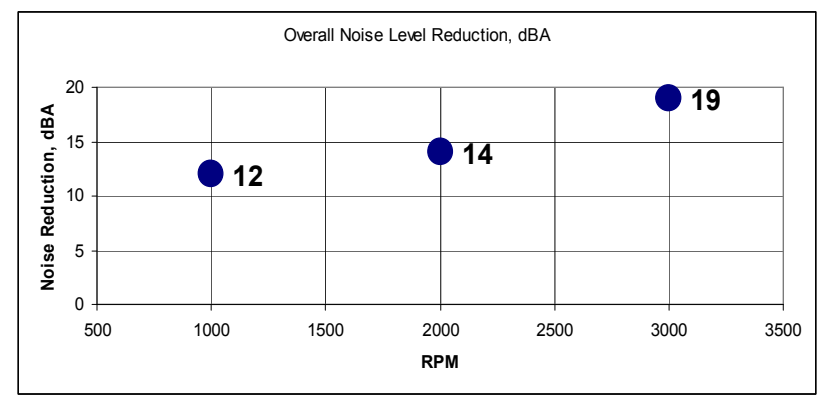

Figure 23. Overall noise level reduction.

The following planned step of implementation of 3D point contact tooth gears is the preparation of documents and paperwork for US Patent application.

\section{Conclusion}

The proposed transmission having gears with 3-D point contact interaction of teeth provides the effective solution for gearing load capacity optimization and noise level reduction during operation.

Owing to extended properties of new teeth profiles it is possible to increase the value of working contact stresses with parallel reduction of emitting noise levels. The novel type of teeth gears in comparison to conventional gears has a load capacity for contact stresses: higher in $1.7-2.4$ times, for bending stresses: lower in $1.4-1.7$ times.

The successful implementation of a transmissions with gears designed with invented point contact interaction of teeth demonstrates the reduction of the sizes and weights of transmissions in $25 \%-40 \%$.

The implementation of new type of modified teeth gears in transmissions gives the opportunity improves radically the acoustical performance of transmission operation, and obtains the significantly low levels of noise. The documented overall noise level reductions are $12 \mathrm{dBA}-19 \mathrm{dBA}$.

The implementation of proposed technology of ship reducer manufacturing gives a qualified chance in the successful fighting with marine noise pollution.

\section{References}

[1] D. Ross, On Ocean Underwater Ambient Noise. Institute of Acoustics Bulletin, St Albans, Herts, UK: Institute of Acoustics, 18. 1993, pages 5-8.

[2] Megan F. McKenna. Donald Ross, Sean M. Wiggins, John A. Hildebrand. Underwater radiated noise from modern commercial ships. Journal of Acoustic Society of America. 131 (1), January 2012, pages 92-103.

[3] Mark A. McDonald, John A. Hildebrand, Sean M. Wiggins, Donald Ross. A 50 Year comparison of ambient ocean noise near San Clemente Island: A bathymetrically complex coastal region off Southern California. Journal of Acoustic Society of America. 124 (4), October 2008, pages 1985-1992.

[4] IFAW. Ocean Noise: Turn it down. A report on ocean noise pollution. June 2008. 42 pages.

[5] Linda S. Weilgart. The Impact of Ocean Noise Pollution on Marine Biodiversity. Ocean Noise Coalition. Report. Halifax, Canada, 2009. 6 pages.

[6] Hertz H. Über die Berührug fester elastisher Körper / H. Hertz. // J. für Reine und Angewandte Mathematik. 1881. — Bd. 92.

[7] Hertz H. Über die Berührug fester elastisher Körper und über die Härte / H. Hertz // Varhandlungen des Vereine zur Beforderung des Geverbefleisses. - Berlin. Nov.1882.— 449 pages.

[8] Hertz H. Gesammele Werke / H. Hertz. — Leipzig. 1895. Bd. 1. - S. 155-196.

[9] Alexei P. Popov. Contact Strength of Geared Mechanisms. Nikolaev. NUK, 2008. 580 pages.

[10] Alexei P. Popov. Geared Mechanisms with point contact of teeth. Nikolaev. ATOLL, 2010. 774 pages.

[11] D. N. Reshetov. Parts of Machines. Moscow. Machine-building. 1963. 723 pages.

[12] Shuting Li. Finite element analyses for contact strength and bending strength of a pair of spur gears with machining errors, assembly errors and tooth modifications. Mechanism and Machine Theory, Vol. 42, 2007, pages 88-114, 
[13] A. Kahraman, R. Singh. Interactions between Time-varying Mesh Stiffness and Clearance Non-Linearities in a Geared System. Journal of Sound and Vibration, Vol. 146,135-156, 1991.

[14] L. Walha, T. Fakhfakh, M. Haddar. Nonlinear dynamics of a two-stage gear systems with mesh stiffness fluctuation, bearing flexibility and backlash. Mechanism and Machine Theory, Vol. 44,1058-1069, 2009.

[15] Konstandinos G. Raptis, Theodore N. Costopoulos, Georgios A. Papadopoulos and Andonios D. Tsolakis. Rating of Spur Gear Strength Using Photoelasticity and the Finite Element method, American Journal of Engineering and Applied Sciences, 2010,3(1), pages 222-231.

[16] Faydor L. Litvin, Alfonso Fuentes, Claudio Zanzia, Matteo Pontiggiaa. Design, generation, and stress analysis of two versions of geometry of face-gear drives. Mechanism and Machine Theory. Volume 37, Issue 10, October 2002, Pages 1179-1211.

[17] J.J. Kalker, Transient rolling contact phenomena. Proceedings 25th ASLE meeting, Chicago, Ill. ASLE, New York, 1971, pages 177-184

[18] J. J. Kalker, On the uniqueness of contact problems in the theory of elasticity, Report 387, Laboratory of engineering mechanics,Delft University of Technology. 1971

[19] J.J. Kalker, A survey of the mechanics of contact between solid bodies. Zeitschrift für Angewandte Mathematik und Mechanik 57. 1977, pages T3-T17.

[20] Biot M. A., 1937, "Bending of an infinite beam on an elastic foundation," Journal of Applied Mechanics Transactions of the ASME, Vol. 59, A1-A7.

[21] Bowles, J. E., 1968, Foundation Analysis and Design, McGraw-Hill Book Co., New York.

[22] Cheung, Y. K., and Zienkiewicz, O. C, 1965, "Plates and tanks on elastic foundations- An application of finite-element method," International Journal of Solids and Structures. Vol. 1, pages 451-461.

[23] R. V. Fediakin, V.A. Chesnokov. Calculations for cylindrical Novikov's transmissions and friction transmissions. Proceeding of VVIA. Moscow. 1982. 144 pages.

[24] M. I. Makushin. Stressed condition and strength in contact. Proceedings of Department of Resistance of Materials. MVTU. Moscow. 1947, pages $79-145$.
[25] George Nerubenko et al. Atlas of Gear Boxes and Transmissions. Nikolaev, 1990. 32 pages

[26] George Nerubenko et al. The exploitation of ship deck mechanisms. HANDBOOK. Moscow, Transport, 1991. 198 pages.

[27] VNIIMASH. Novikov's transmission with tooth surface hardness $H B>350$. Strength calculations. Methodical recommendations. Moscow. 1987. 86 pages.

[28] IMASH RAN. Influence of sag on determination of load in gearing and between satellites in planetary transmission. Moscow. 2009. 30 pages.

[29] Alexei P. Popov. Gear Mesh. Ukrainian Patent № 77634. Published 15.12.2006.

[30] Alexei P. Popov. Gear Transmission of Popov A. P. Ukrainian Patent № 81008. Published26.11.2007.

[31] Alexei P. Popov. Gear Transmission with equally strengthen mesh of involute teeth. Ukrainian Patent №84606. Published 10.11.2008

[32] Davis, J. Gear Materials, Properties and Manufacture. Materials Park OH: ASM International. 2005.

[33] Dudley, D. W. Handbook of Practical Gear Design. Lancaster: Technomic Publishing Company. 1994.

[34] Mats Åkerblom. Gearbox Noise, Correlation with Transmission Error and Influence of Bearing Preload. Doctoral Thesis in Machine Design. Department of Machine Design. Royal institute of Technology. SE100 44 Stockholm, Sweden. 2008.

[35] Shawki S. Abouel-Seoud, Eid S. Mohamed, Ahmed A. Abdel-Hamid, Ahmed S. Abdallah. Analytical Technique for Predicting Passenger Car Gearbox Structure Noise Using Vibration Response Analysis. British Journal of Applied Science \& Technology. 3(4): 2013, pages 860-883.

[36] Satya D. Pradhuman. Cirrus Research. Approach and Methodology. 303 S. Broadway, Suite 212, Tarrytown, New York 10591. 2010.

[37] William J. Atherton, Adam Pintz, David G. Lewicki. Automated Acoustic Intensity Measurements and the Effect of Gear Tooth Profile on Noise. Cleveland State University. 1987. Mechanical Engineering Faculty Publications. Paper 4. 